no schemes for dealing with the position in Pakistan, in Israel and in Turkey. Even with the help of the Colombo Plan many Pakistan universities and libraries were unable to obtain the British books they need, and their science faculties had lacked all specialist periodicals over the past ten years; there was an unsatisfied annual demand there for $£ 50,000$ worth of British books and $£ 15,000$ worth of periodicals. The Earl of Gosforth, in concluding the debate, made no specific comment on this situation, but promised that all suggestions made in the debate would be carefully considered.

\title{
HOSPITAL SERVICES IN GREAT BRITAIN
}

\begin{abstract}
HE debate on the hospital services in Britain, in the House of Lords on July 2 , opened by Lord Nathan, was noteworthy both for the review of the first ten years operation of the National Health Service and for the stress which was laid upon medical research by Lord Nathan himself and other speakers. Lord Nathan said that while there had been no increase in the number of teaching hospitals, the number of beds had increased from 26,000 to nearly 28,000 , and in the non-teaching hospitals from 475,000 to 481,000 ; the bed-occupancy had remained at just over 80 per cent in the teaching hospitals and increased from 79 to 83 per cent in the non-teaching hospitals. The medical and dental staff over the whole country had increased by about 30 per cent, and in the teaching hospitals the number of nurses had increased by 20 per cent, but only by 10 per cent in the non-teaching hospitals, where the number of out-patients was now about 18.5 million a year, compared with 9.5 million in the teaching hospitals in 1956 (an increase of 2 million on 1949). Lord Nathan referred to the increase in voluntary service in the hospitals, to the increased space demanded by new developments in surgery and treatment and, finally, to the extreme importance of research, including the value of sending staff abroad to study methods used elsewhere. We could not expect to retain in our hospitals or in Britain men of the right quality unless we provided them not merely with adequate remuneration but, even more important, with the opportunities for developing their powers and their careers within their profession to the utmost. As regards costs, Lord Nathan said that the Guillebrand Committee found that capital expenditure in 1952-53 was only one-third what it had been in 1938-39, and he added that running costs for 1958-59 were estimated at just under $£ 400$ million, an increase of 4 per cent on 1957-58.

Other points emphasized in the debate were the shortage of accommodation for elderly persons, the
\end{abstract}

vital importance in the teaching hospitals of the personal influence of the teacher on the student. Lord Evans stressed the dependence of the standard of of our teaching hospitals upon this personal contact between teacher and student. He also suggested that the hospitals should be encouraged to seek additional sources of finance. Lord Moran referred to the importance of the redistribution and the increase in number of consultants, so that there were now available in almost every part of the country first-rate specialists in every branch of medicine, and he sup. ported Sir George Pickering's suggestion that every drug in the Pharmacopœia should be investigated to see when it is necessary as the only way to reduce the drug bill of $£ 74$ million a year. Lord Addison said a brake might be placed upon research generally in teaching hospital groups, because of the difficulty in handing over to the Exchequer vote methods result. ing from research activities after they had taken their place in normal clinical procedure, and suggested that some more frequent method of assessing the stages to which research had developed might be advantageous. Reference was also made to the great advance in the treatment of mental diseases, but Lord Pakenham thought that an expenditure of only 2 per cent of its funds by the Medical Research Council on research into mental health was inadequate.

In his reply for the Government, Lord Strathclyde pointed out that, since the Guillebrand report, capital expenditure had considerably increased and was now about $£ 23$ million compared with $£ 12$ million in 1952-53. He states that the Government fully realized the importance of research, and said that it fully accepted the value of travelling scholarships and that hospital boards had been given very considerable discretion to grant study leave. In 1948-57, $£ 18$ million out of a capital expenditure of $£ 70$ million had been spent on mental hospitals, and the percentage had risen from 23.9 in $1948-56$ to 32.7 in 1956-57. The Government was also fully alive to the potentialities in the application of work study.

\section{TRANSPLANTATION OF THE FOREBRAIN REGION IN BIRD EMBRYOS BEFORE THE ESTABLISHMENT OF A CIRCULATION}

\section{Homoplastic Transplants}

$I_{\text {tat }}^{\mathrm{N}}$ a recent publication one of us described a technique by which the forebrain region of chicken embryos at the stage of development prior to the establishment of a circulation can be transplanted to hosts of a corresponding stage ${ }^{1}$. Successful autoand inter-breed homo-transplants have been obtained. Some of the grafted embryos, including the graft, continued to develop in a fairly normal way up to the time of hatching. Further work with the fore- brain grafts showed that some of the grafted embryos are capable, with very little assistance, of freeing themselves from the shell, and living thereafter for considerable periods. So far, five such animals have been obtained. Of these, one was an autografted Rhode Island Red, three were homografted Rhode Island Reds and one was a Rhode Island Red on to which the forebrain of a Barred Rock Black embryo was grafted. The autografted chick was killed $77 \mathrm{hr}$. after hatching. One homografted chick died $30 \mathrm{hr}$, another $36 \mathrm{hr}$. and the third 55 days after 